\title{
Crackles: recording, analysis and clinical significance
}

\author{
P. Piirilä*, A.R.A. Sovijärvi**
}

Crackles: recording, analysis and clinical significance. P. Piirilä, A.R.A. Sovijärvi. @ERS Journals Ltd 1995.

ABSTRACT: Crackles are short interrupted breath sounds usually associated with pulmonary disorders. According to present opinion, a crackle is generated when an abnormally closed airway opens during inspiration or closes at the end of expiration. The timing of crackles in breathing cycles can be assessed with phonopneumography, their duration with time-expanded waveform analysis, and their pitch with analysis of frequency spectra. The timing, pitch and waveform of crackles are different in pulmonary disorders reflecting different pulmonary pathophysiology.

This review deals with the genesis, auscultation, recording and analysis of crackles, with an emphasis on modern signal-processing methods.

Eur Respir J., 1995, 8, 2139-2148.

\begin{abstract}
*Laboratory of Clinical Physiology, Finnish Institute of Occupational Health, Helsinki, Finland. **Laboratory of Clinical Physiology, Division of Pulmonary Medicine and Clinical Physiology, Dept of Medicine, Helsinki University Hospital, Helsinki, Finland.
\end{abstract}

Correspondence: A.R.A. Sovijärvi, Laboratory of Clinical Physiology, Helsinki University Hospital, 00290 Helsinki, Finland

Keywords: Crackles, lung sounds, pulmonary diseases, sound analysis

Received: January 31995

Accepted after revision March 311995
Crackles are short explosive breath sounds, usually associated with pulmonary disorders and heart failure. Crackling sounds have been shown to vary in character in different pulmonary diseases when listened to through a stethoscope. The auscultatory findings have been shown to be related to histological alterations of pulmonary tissue and functional impairment in interstitial pulmonary diseases [1].

The study of crackling lung sounds began with the invention of the stethoscope by Laënnec in 1816. "Auscultation Mediate" a treatise by LAENNEC [2] contains a description of the auscultatory findings of normal and adventitious pulmonary sounds, which he related to autopsy findings. Perhaps the first graphic presentation of recorded crackling sounds was that by CABOT and DODGE [3] in 1925. Studying the frequency characteristics of heart and lung sounds by using bandpass filters, they showed that crackles defined as fine in pulmonary auscultation contained higher frequencies than those defined as coarse. In 1955, McKusick et al. [4] displayed sound spectrograms of normal, vesicular, tracheal, bronchovesicular, and asthmatic sounds. They also presented spectrograms of crackles classified in auscultation as moist or dry.

The first phonopneumographic recordings of crackling sounds were presented in the 1970s [5-7]. ForGACs [5, 8] stated that pulmonary crackles were generated during inspiration as a result of sudden opening of the airways. Therefore, the size and properties of the airways could affect the character of a crackle. Since the presentation of this theory, advanced studies on crackling sounds have been conducted using sound spectrography $[9,10]$, phonopneumography [6, 7], time-expanded waveform display [11-14] and Fast Fourier Transform analysis [11, $13,14]$. These studies have not been able to refute Forgacs' theory.

This review article deals with present theories of the genesis of crackles, methods for auscultation, recording and analysis of crackles, and clinical applications of crackle studies.

\section{Genesis of crackle sounds}

In the past, it was commonly believed that crackles were generated by bubbling of air in the airways or from the motion of intraluminal secretions. The persistence of crackles after coughing, and their repetitive nature in consecutive inspirations, contradict this theory [5-7]. Crackles are nowadays thought to be caused by the sudden opening of abnormally closed airways. According to the theory of FORGACS [5, 8], in inspiration, a gradient of gas pressure is developed across airways that are collapsed during expiration. A popping crackle sound is generated when a closed airway suddenly opens during inspiration or closes during expiration, thus inducing a rapid equalization of gas pressures and a pressure wave. Each crackle may represent an abrupt opening or closing of a single airway. This theory has received further support from the work of NATH and CAPEL [7], who found that the individual crackles occurred at similar inspired volumes and transpulmonary pressures during consecutive inspirations.

FREDBERG and HOLFORD [15] have postulated a mathematical theory of stress-relaxation quadrupoles, which is in accordance with the sudden opening theory of 
FORGACS [5, 8]. However, their theory assumes that when an airway opens, sudden changes occur in elastic stress, i.e. increase in stress and its relaxation in and near the airway walls. Accordingly, dynamic events in the airway wall and in their surroundings rather than differences in gas pressure would create the sound waveform of a crackle, which would spread from its site of generation.

Crackles usually occur when the elastic recoil pressure of the lungs is increased, or there is inflammation or oedema in the lungs. The character of the crackling sounds possibly depends on the diameter of the airways which are closing and opening, and this in turn depends on the pathophysiology of the surrounding tissue $[5,15]$. It has been shown experimentally that the characteristics of crackles produced in airway models vary with the size of the airways; smaller airways have been shown to produce crackles of shorter duration [15]. Early inspiratory crackles are probably generated in more proximal airways than late inspiratory crackles. In chronic bronchitis and emphysema, collapse of the lobar bronchi may occur at end-expiration due to loss of elastic recoil and bronchial support [16]. In fibrosis, the process usually involves peripheral airways, the distribution of airway closure being gravity-dependent. The count and distribution of crackles also depend on the disease process and its severity [1].

Crackles have also been detected in the breath sounds of normal subjects $[1,17,18]$. THACKER and KRAMAN [19] found crackles in the lung sounds of normal volunteers recorded over the anterior chest during inspiration starting from residual volume level, but not when they inspired from functional residual capacity level. These crackles varied considerably in pitch and duration. Thus, crackles may not always be an indication of pathological pulmonary processes, but their occurrence depends also on the expired volumes during auscultation. The basal alveoli of a normal lung, deflated at the residual volume, inflate in late inspiration; the basal airways are the first to close towards the end of expiration [20]. Therefore, crackles will most often appear at the early stage of a disease at basal areas of the lungs. With ageing, when the elastic recoil pressure of the lungs decreases the incidence of crackling sounds tends to increase [21].

Crackles may disappear during pulmonary auscultation procedures repeated several times at short intervals, or during pulmonary function tests after vital capacity manoeuvres. This is possibly due to the effect of lung expansion. When regions of deflated airways open, the number of crackles is decreased.

\section{The auscultation of crackling lung sounds}

LAËNNEC [2] described the following types of crackles listened through his wooden cylinder stethoscope: 1) humid or crepitous crackles; 2) mucous or gurgling crackles; 3) dry sonorous crackles; and 4) dry sibilous or hissing crackles. The characterization of crackles according to the "dryness" or "humidity" of the sounds is no longer recommended. The modern classification is based on the pitch and duration of the crackling sounds. In the present terminology of auscultation, the crackles belong to adventitious (not normally occurring) sounds. In contrast to continuous (wheezing) adventitious sounds they are called discontinuous sounds. The terms fine crackles to characterize crackles with high frequency components and short duration, and coarse crackles for crackles with lower frequency and longer duration are recommended by the American Thoracic Society (ATS) (table 1) [22]. Also, the timing of crackles in the respiratory cycles must be characterized. Crackles may appear in early, mid- or end-inspiration or expiration.

Because of the very short duration and often low intensity of the crackles, their discrimination and characterization by normal auscultation is difficult. Moreover, the linguistic descriptions of crackle sounds by different physicians are various. There are differences in physicians' hearing properties as well as in the stethoscopes. The maximal sensitivity of the ear is normally at the frequency range of $1-2 \mathrm{kHz}$. Below $1,000 \mathrm{~Hz}$, and especially below $500 \mathrm{~Hz}$ [23], the sensitivity of the ear falls sharply. The frequency response of stethoscopes varies greatly depending on the type of stethoscope, and there are also great individual differences between them. Stethoscopes have been shown to considerably attenuate all sound frequencies in a nonuniform way in several studies where both the diaphragm and bell chest pieces have been used [24-28].

There are also several other factors which influence the hearing of crackling sounds. The sensitivity of the ear to different sound frequencies depends on the relative loudness of the sound $[29,30]$. The ability of the ear is poor in recognizing a tone of very short duration [31]. There are also difficulties in hearing short sounds separated from each other by very short intervals. The minimum audible time interval for the separation of sounds also depend on the frequency composition and intensity of the sounds to be separated [32].

The low pitched components of a complex sound appear more prominent to the observer when the sound is loud, because low pitched sounds mask the higher pitched sounds; and vice versa, when the intensity of the sound

Table 1. - The classification of crackles according to ATS [22] based on lung sound analysis results: sound recording and filtration procedure affect the waveform characteristics and crackle sound parameter durations

\begin{tabular}{lccccc}
\hline & Intensity & Pitch & 2CD duration & IDW duration & Other terms \\
\hline Coarse crackles & Loud & Low & About $10 \mathrm{~ms}$ & About $1.5 \mathrm{~ms}$ & $\begin{array}{c}\text { Bubbling rales, } \\
\text { coarse crepitations } \\
\text { Fine crackles }\end{array}$ \\
\hline
\end{tabular}

ATS: American Thoracic Society; 2CD: two cycle duration; IDW: initial deflection width. 
attenuates, the high frequency components of the sound accentuate [33, 34]. Moreover, when a sound of relatively great intensity precedes a sound of low intensity, the greater intensity has a tendency to fatigue the ear and the low intensity sound gets masked; the ear, thus, fails to sense some sounds $[30,35]$.

Semantic factors, clinical routines, and the physician's personality influence the description of auscultatory findings. Therefore, the interobserver variability between clinicians in describing the auscultatory finding of crackles has been great. When determining the presence or absence of abnormal lung sounds in cotton workers, SHILLING et al. [36] reported that two observers had an interobserver error of $24 \%$. In a study by SMYLLIE et al. [37], the interobserver repeatability of respiratory physical signs was about midway between complete agreement and chance. HuDSON et al. [38] reported $47 \%$ agreement of three observers to assess whether the crackles were fine, medium or coarse, and moist or dry. In these studies, the observers were not well-trained.

In a study by WORKUM et al. [18], especially trained observers assessed the presence or absence of crackles by listening to tape-recorded breathing sounds of asbestosexposed workers. Two observers' agreement was $89 \%$, and four observers' agreement $81 \%$. In a study by the authors of this review [39], two observers tried to classify crackles by listening to tape-recorded crackling lung sounds which had previously been analysed by computerized waveform analysis; 10 samples included fine crackles of fibrosing alveolitis and 10 coarse crackles of heart failure. The observer agreement on the coarseness or fineness of the crackles was $60 \%$. The percentage of wrong classification was higher, 70 and $90 \%$ in samples from patients with fibrosing alveolitis, and 80 and $60 \%$ from patients with bronchiectasis, respectively. These studies elucidate the great difficulties and variations in the description of auscultatory findings. In lung auscultation, the agreement is better when there is only a question of the presence or absence of abnormal sounds; the agreement is poorer the more characteristics that have to be taken into account, such as grading or timing of sounds.

\section{Recording and analysis of crackling sounds}

The lung sound recording systems usually consist of a pneumotachograph for airflow or volume measurements, and microphones and a tape-recorder for sound capturing. In phonopneumography the sound intensity signal is displayed simultaneously with the airflow (or air volume) signal. The crackling sounds can usually be visualized as transient peaks in the sound signal (fig. 1). Phonopneumographic recording serves as the basic method in analysis of crackle sound timing; the time or volume of occurrence of the crackles can be accurately measured. The following timing parameters can be used: beginning of crackling (time interval from the beginning of a respiratory cycle to the first crackle in relation to the duration of the whole respiratory cycle) and end-point of crackling (the distance from zero flow to the last crackle, respectively) [13].

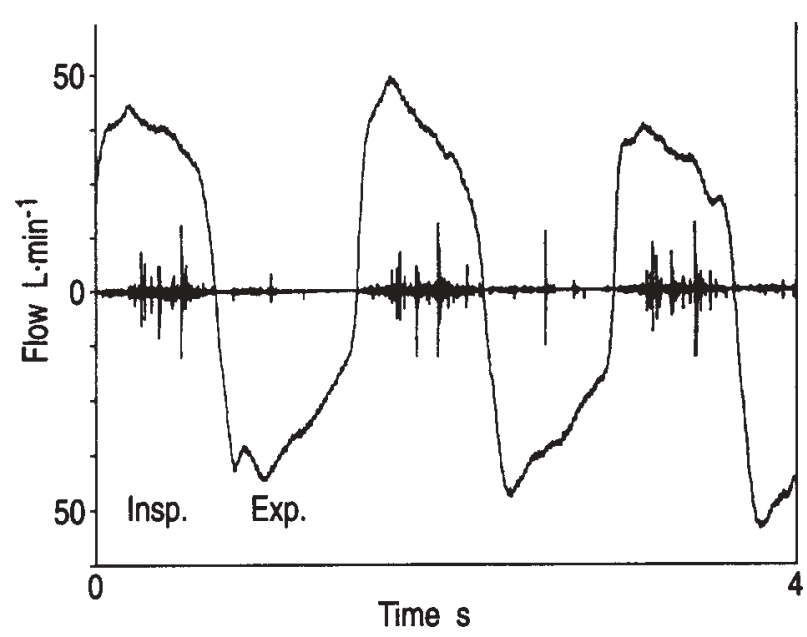

Fig. 1. - A phonopneumogram (simultaneous presentation of lung sound and airflow signals) of the breath sounds of a patient with fibrosing alveolitis, showing late inspiratory (Insp) crackling as sharp peaks in the sound signal. Some expiratory (Exp) crackles are also shown. (Reproduced by permission of Bull Eur Physiopathol Respir, Dalmasso et al. [11]).

Phonocardiographic microphones have been used in the first lung sound recording systems [6, 7, 40, 41], but their low sensitivity and their narrow frequency response band limit their application for further lung sound analysis. DRUZGALSKI et al. [42] found air-coupled condenser microphones suitable for lung sound recordings. At present, piezoelectric microphones are also used [43-46]. The techniques of attachment and placing of microphones have varied; some researchers have used a belt [13] or rubber tape attachments [46, 47], and some hold microphones by the hand [48].

Sound signals are usually recorded on magnetic tape or stored in digital form in computer memory. In lung sound analysis, the frequency response band of the whole recording and signal processing equipment is highly important. Direct mode tape-recorders have been used in some studies [49-53]. The frequency response of direct mode recorders is variable; they attenuate low frequency components like a high-pass filter with a cut-off frequency of 50-200 Hz. In many studies, frequency modulation (FM) tape recorders are used, with adequate frequency response both at low and high frequency bands.

High-pass filters are frequently used in lung sound recordings to diminish low frequency noise, possibly generated by muscles, large blood vessels and the heart [48, $54,55]$. There has been a controversy about the clinical significance of the low frequency sounds recorded, since some researchers have suggested that the low frequencies may also originate in the lungs $[56,57]$. The high-pass cut-off frequency has varied markedly in recent studies: no prefiltration [56, 57], $>50 \mathrm{~Hz}[48],>75 \mathrm{~Hz}$ [44], $>100 \mathrm{~Hz}[13,58],>200 \mathrm{~Hz}[59]$, and $>600 \mathrm{~Hz}[6,7]$. In several studies, different bandpass filters have been applied: $50-2,000 \mathrm{~Hz}$ [43], $100-3,000 \mathrm{~Hz}$ [10], 150$350 \mathrm{~Hz}$ [47], and 150-700 Hz [60].

FORGACS [5] used a somewhat expanded time scale for displaying crackling sounds. In this way, late and early crackles and their repetitive nature could be demonstrated. Murphy et al. [49] expanded the time scale to 
$800 \mathrm{~mm} \cdot \mathrm{s}^{-1}$, thus allowing a detailed analysis of the waveform of crackles. They demonstrated the waveforms of normal vesicular and tracheal inspiratory sounds, rhonchi, wheezing sounds and inspiratory crackles. At the moment, time expansion up to $2,000-6,000 \mathrm{~mm} \cdot \mathrm{s}^{-1}$ is commonly used in lung sound research.

In the sonographic analysis, a frequency spectrum of the sound is displayed in time domain $[4,9,10,51]$. This method has not yet been widely used in the analysis of crackling sounds. Recently, however, computerized sonogram analyses of crackling sounds have been published [46, 61-63]. In sonographic display, a crackle appears as a sharp and high intensity peak with frequency components up to $4 \mathrm{kHz}[11,61,62]$.

Since the 1970s, computer-aided systems have been used for lung sound analysis using Fast Fourier Transform (FFT) spectrum analysis [64]. One of the first studies using FFT spectrum analysis was conducted in 1973 by MURPHY and SORENSEN [17], who studied crackles in asbestosis patients. In FFT spectrum analysis, the amplitude of the sound signal is presented in frequency domain. Several studies of crackles have been carried out on the FFT analysis $[11,13,14,65]$. Serial FFT spectra have clearly demonstrated high frequency components of crackles, e.g. in patients with pneumonia [14].

The variation of the second quartile frequency of averaged FFT spectrum (F50) in lung sound samples recorded 1-3 days apart, has recently been shown to be slightly higher in patients with fibrosing alveolitis, having crackles in their breath sounds, than in healthy subjects [66].

\section{Crackle waveform}

Time-expanded waveform analysis has revealed that a crackle begins with a short initial deflection followed by deflections with greater amplitude. A true crackle has an amplitude of deflection which is two times as large as the amplitude of the background [67]. HOLFORD [12] studied crackles classified into coarse or fine by a pulmonary specialist. He measured the duration of the initial deflection width (IDW) and the two cycle duration (2CD) determined as the time from the beginning of IDW to the point where the crackle has completed two cycles (fig. 2). IDW and $2 \mathrm{CD}$ have been used to classify crackles as coarse or fine (fig. 3). Suggestions for reference values for fine and coarse crackles have also been presented [22, 65, 68]; according to ATS suggestion [22], the mean durations of IDW and 2CD of fine crackles are 0.7 and $5 \mathrm{~ms}$ and those of coarse crackles $1.5 \mathrm{~ms}$ and $10 \mathrm{~ms}$, respectively (table 1).

Hoevers and Loudon [69] have suggested a third crackle waveform index, the largest deflection width (LDW). This is defined as the duration of the deflection with the largest amplitude in the crackle waveform. They found that LDW was a good parameter in classifying crackles into fine and coarse, even better than IDW. LDW has also proved to be a good index to classify crackles for diagnostic purposes [13], or in the follow-up of a pulmonary disease [14]. Sometimes, it is difficult to determine

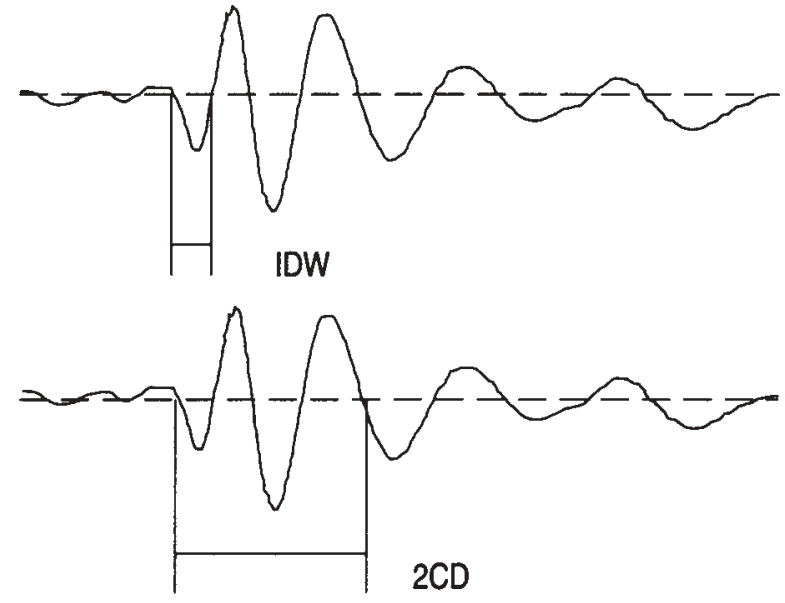

Fig. 2. - The morphology of one crackle in time-expanded waveform display in high-pass filtered recording. The crackle parameters: IDW = initial deflection width; $2 \mathrm{CD}=$ two-cycle duration, are presented. (Reproduced by permission of the Massachusetts Institute of Technology, Holford [12]).

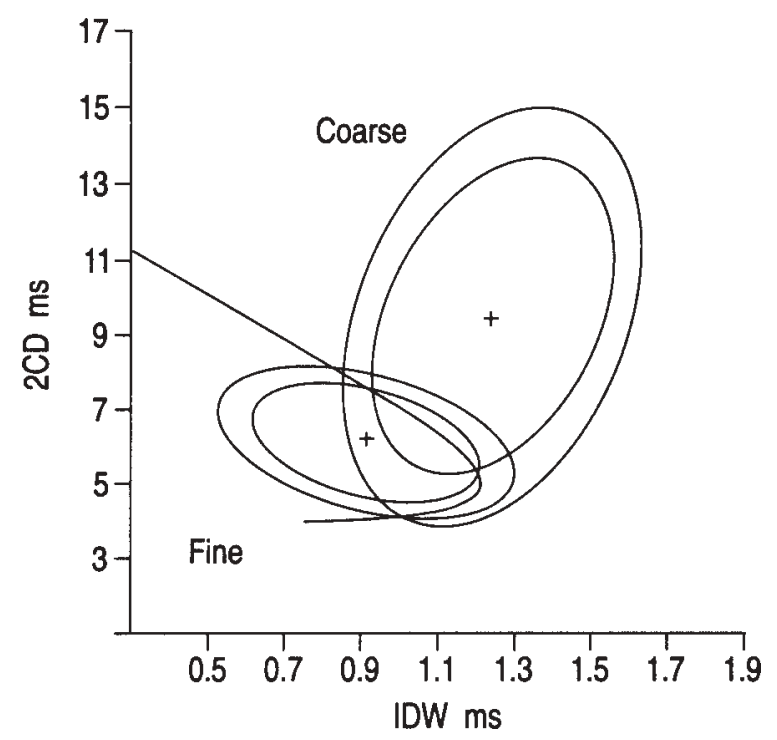

Fig. 3. - The discrimination of crackles into fine and coarse by using twocycle duration (2CD) and initial deflection width (IDW). (Reproduced by permission of the Massachusetts Institute of Technology, Holford [12]).

the exact beginning of a crackle needed for the measurement of IDW and 2CD. This difficulty does not arise in the measurement of LDW.

The duration of IDW and 2CD has varied greatly in different studies [13, 14, 22, 65, 68]. Since the high-pass filtration in these studies also varied, we conducted experiments in which inspiratory crackling sounds in a patient with silicoasbestosis were recorded in an anechoic room without any high-pass filtration [58]. The waveform of the crackles recorded in this way was simply monopolar or bipolar without any further deflections. When progressively filtered with different high-pass levels, the waveform of the crackles gradually reached the morphology presented in some earlier studies [12, 49] (fig. 4). Sometimes, the polarity of the initial deflections of crackles also changed with filtration of the sound signal. Based on this experiment, it was apparent that the waveform of a 


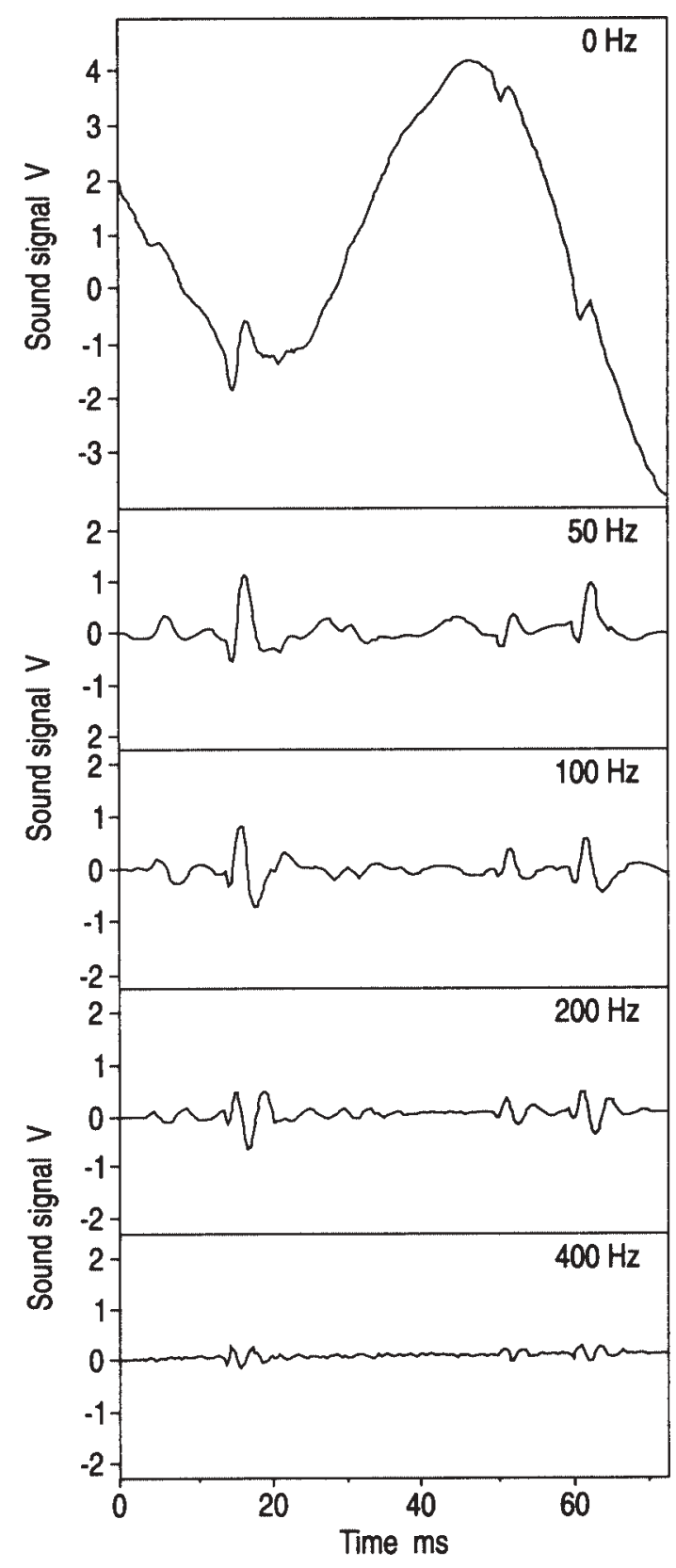

Fig. 4. - The end-inspiratory fine crackles of a patient with silicoasbestosis in time-expanded waveform display without any highpass filtering $(0 \mathrm{~Hz})$. The filtration effect of progressive filtering with 50, 100, 200 and $400 \mathrm{~Hz}$ analogue filtration is shown below [61].

crackle with several oscillations is a consequence of highpass filtration, actually an artefact, and that the original waveform is simpler [58]. Also, the great variability in the duration of the crackle parameters reported in the literature in similar diseases could be explained by the differences in the filtration or recording methods used.

In the filtration study cited above [58], it was also found that, in auscultation, only inspiratory crackling sounds could be recognized. However, in the nonfiltered taperecorded lung sound signal, there were similar deflections in expiration also but in the opposite direction to inspiration. These expiratory deflections may represent sounds generated by airways closing at the end of expiration, thus fitting in with Forgacs' theory of the genesis of crackles.

However, it is very difficult to study crackles without any high-pass filtration, due to the slow background oscillation of the sound pressure. International recommendations for filtration have not yet been given. A European Community (EC) project (Computerized Respiratory Sound Analysis (CORSA) project) of seven European countries to develop guidelines for standardized recording and analysis of respiratory sounds, led by A.R.A. Sovijärvi, has recently been started. When the details of filtration and the frequency characteristics of the recording devices are indicated and standardized, high-pass filtered respiratory sound signals may be used to determine IDW, 2CD and LDW for the assessment of different pulmonary diseases. To enhance the diagnostic discrimination power, simultaneous analysis of the waveform and timing characteristics of crackles, i.e. two-dimensional discriminant analysis, can be applied, according to our recent discovery [70].

\section{Automatic counting of crackles}

The number of crackling sounds possibly indicates the severity of the pulmonary disease at least in fibrosing lung diseases $[1,71]$. Because the human ear may fail to detect the right number and character of the crackles, automatic counting methods have been developed [62, 67]. In the sonogram analysis, crackles can be distinguished as narrow peaks of high frequency and short duration. Spectral and waveform differences of the crackle sounds compared to the surrounding vesicular lung sound signal make identification of the crackles possible.

An automatic crackle counting method by MurPHY et al. [67] showed a good agreement with the counts obtained by two expert observers who listened to taperecorded sounds $(\mathrm{r}=0.74)$, and with the crackle counts detected by visual inspection in time-expanded waveform display $(\mathrm{r}=0.85)$. Another automatic method to detect and count crackles has recently been published by the authors of this review [62]. The method was based on the analysis of spectral stationarity of the sound signal. It was validated by the counting of crackles in timeexpanded waveform display by two expert observers. The method indicated a high sensitivity (89\% in fibrosing alveolitis and $80 \%$ in bronchiectasis) and a high positive predictivity $(88 \%$ in fibrosing alveolitis and $83 \%$ in bronchiectasis). The correlation coefficient between automatic crackle counting and counts by the observers was 0.86 in fibrosing alveolitis and 0.93 in bronchiectasis.

The automatic counting methods enable large sound materials to be studied with the same standardized detecting and counting criteria. Automatic determination of the timing of crackles and the measurement of waveform indices will be possible in the near future. With this type of method, the possibility of analysing lung sounds for differential diagnosis of pulmonary diseases will be enhanced. 


\section{Clinical applications of crackles}

The waveform, timing, number and regional distribution of crackles are associated with the severity and character of the underlying pulmonary disorder. The assessment of crackle is beneficial for early diagnosis and follow-up of the disease. In diffuse interstitial pulmonary diseases, the crackles first appear in the basal areas of the lungs and later, as the disease progresses, also in the upper zones of the lungs. In heart failure with pulmonary congestion, crackles are best heard in the lower zones of the lungs, but in profuse heart failure over the entire chest wall; this phenomenon had already been reported by LAËNNEC [2]. The appearance of crackles has been considered to be an early sign of pulmonary impairment in asbestosis [1, 10, 72]; in early disease, crackles have been described to appear first in the basal pulmonary areas, later successively higher up on the thorax [73]. On rare occasions, e.g. in severe heart insufficiency, crackles are audible at the mouth [5].

\section{Crackles in pulmonary fibrosis}

Nath and CAPEL $[6,7]$ showed that late inspiratory crackles occurred in restrictive pulmonary diseases. DALMASSo et al. [11] described the timing of crackles in fibrosing alveolitis; the crackles started early or at midphase in inspiration but continued to the end of inspiration. In another study [13], crackling in fibrosing alveolitis occurred late during the inspiratory cycle; there was no overlap with the early timing of the crackles in COPD (fig. 5).

ChOWdHuRy et al. [74] found spectral differences between normal subjects and patients with fibrotic lesions following tuberculosis. In the study by KUDOH et al. [9], the frequency components of crackles in diffuse interstitial pneumonia were as high as $2,000-5,000 \mathrm{~Hz}$ measured in sonogram spectrography, whereas the frequency of crackles in chronic bronchitis, bronchiectasis or diffuse panbronchiolitis was lower. DALMASso et al. [11] used FFT spectrum analysis in their study of cryptogenic fibrosing alveolitis, and found the frequency of crackles to range $100-2,000 \mathrm{~Hz}$, the spectral energy being below $1,000 \mathrm{~Hz}$. In our recent studies [13], the crackles in fibrosing alveolitis differed markedly from three other pulmonary diseases, bronchiectasis, COPD and heart failure; the crackles in fibrosing alveolitis were the shortest in duration. The $2 \mathrm{CD}$ was below $8 \mathrm{~ms}$ and the frequency of maximum intensity was about $200 \mathrm{~Hz}$.

\section{Crackles in asbestosis}

In patients with pulmonary asbestosis, fine crackles have been described, assessed by pulmonary auscultation with a stethoscope $[5,17,72,75]$. The presence of crackles has been shown to correlate with roentgenological and histological honeycombing [1]. The incidence of crackles in asbestosis is also correlated with the duration of exposure to dust containing asbestos [10]. SHIRAI et al. [10] demonstrated end-inspiratory timing of the

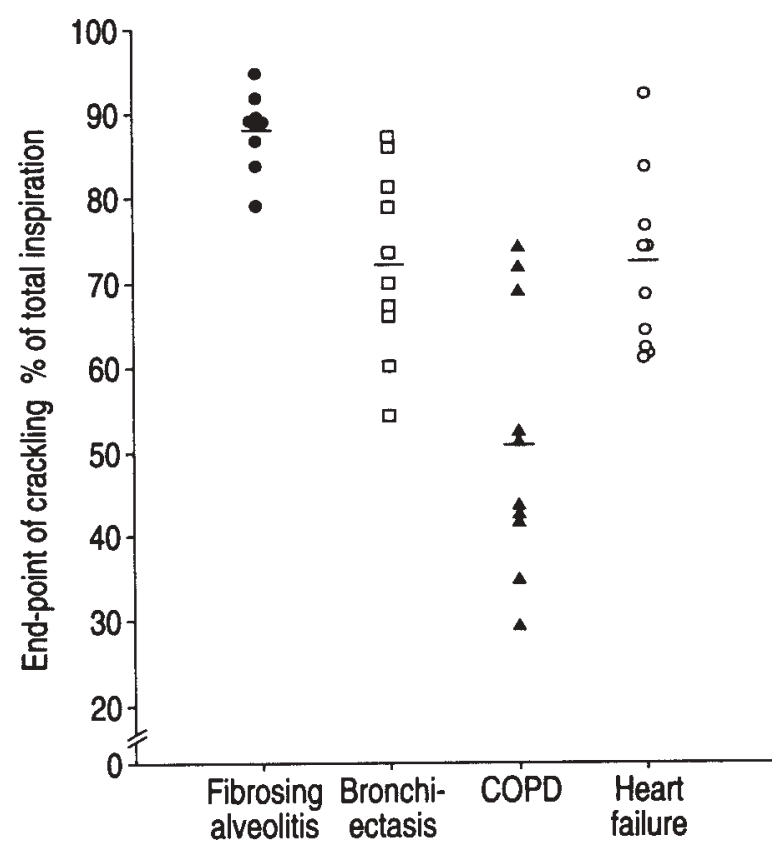

Fig. 5. - The timing in four different pulmonary diseases: cryptogenic fibrosing alveolitis, bronchiectasis, chronic obstructive pulmonary disease (COPD) and heart failure. The timing parameter is the end-point of crackling as a percentage of the whole duration of inspiration. The timing of the crackles in fibrosing alveolitis was significantly different compared to all other diagnoses (mean/median shown by horizontal bar) and there was no overlap between fibrosing alveolitis and COPD. There was also a significant difference in the timing of COPD compared to the timing of crackles in heart failure and bronchiectasis. The horizontal bars indicate mean values of the groups. (Reproduced by permission of Chest PIIRILÄ et al. [13]).

crackles in asbestos workers; the duration of crackles was about $10 \mathrm{~ms}$ and their highest frequency content ranged 1,000-2,000 Hz. MuRPHY and SORENSEN [17] found that the auscultatory scoring of crackling correlated to the duration of exposure in a similar way as the decline of diffusing capacity. They classified the crackles as fine; the frequency components of the crackles were over $500 \mathrm{~Hz}$. AL JARAD et al. [76] have found the crackles in asbestosis to be fine in time-expanded waveform display and their timing to be mid- to late-inspiratory. In addition, they have compared the finding in pulmonary auscultation, plain chest radiography, time-expanded waveform display, and high resolution computer tomography (HRCT). They found that signs of early asbestosis which were not visible in the plain chest radiograph could be detected with time-expanded waveform analysis and HRCT with similar frequency [77].

\section{Crackles in bronchiectasis}

In bronchiectasis, the walls of the large bronchi are abnormally dilated due to destruction of their elastic and muscular components. In expiration, the bronchial walls collapse followed by sudden opening during inspiration. The crackles in bronchiectasis appear in early or midinspiration $[6,7,11]$. Waveform analysis has shown that the crackles in this disease are coarse $(2 \mathrm{CD}>9 \mathrm{~ms})$, and their upper frequency limit is high. An early onset of crackling and its late end-point within the inspiratory 
cycle are also typical of bronchiectasis [13]. The crackles in bronchiectasis are distinguished from the early crackles in COPD, since they occur later during the inspiratory cycle and have a longer duration related to the respiratory phase.

\section{Crackles in COPD}

In COPD, crackles are most commonly caused by airway secretions. These kind of crackles disappear or their auscultation place changes after coughing [5]. In contrast, crackles can sometimes be heard almost constantly in inspiration as well as in expiration. The main cause of this phenomenon is probably sequential closing and opening of proximal bronchi, narrowed as a result of obstruction, due to loss of their cartilaginous support because of inflammation. In lung sound analysis, the crackles in chronic obstruction have been described to be scanty, early and low-pitched [5-7]. In COPD, the crackles are usually few and coarse $(2 \mathrm{CD}>9 \mathrm{~ms})$ starting early in inspiration and ending before the mid-point of inspiration [13]. NATH and CAPEL $[6,7]$ have also documented the early timing of crackles in COPD.

\section{Crackles in heart failure}

The crackling sounds in heart failure have been considered to result from the opening of airways narrowed by peribronchial oedema [5]. LAENNEC [2] described the crackles in heart failure as a slight crepitous mucous rattle, which was difficult to distinguish from the crackles in peripneumony. FORGACs [5] found the crackles in heart failure to be late, high-pitched inspiratory and expiratory crackles. MURPHY [78] has described them as "difficult to distinguish from the crackles of interstitial fibrosis, but more transient, more gravity-dependent". In a paper by HUDSON et al. [38] heart failure patients were reported to have medium crackles in $65 \%$ and dry rales in $88 \%$ of cases. Some other authors have reported fine crackles in heart failure [79]. Crackles in heart failure disappear rapidly as the patient recovers.

In computerized lung sound analysis, the crackles in heart failure have been shown to be the most coarse compared to fibrosing alveolitis, bronchiectasis or COPD [13]. Long duration $(2 \mathrm{CD}>10 \mathrm{~ms}$ ) and a low upper frequency limit of sound were typical to them; they lasted for a long time during the inspiratory cycle and appeared late [13].

\section{Crackles in pneumonia}

In acute pneumonia, oedema and infiltration of inflammatory cells in lung tissue may narrow the bronchi. In resolving pneumonia, inflammatory cells tend to accumulate and oedema diminishes. Consequently, the lung parenchyma becomes drier. Nonuniformly decreased compliance in patients with resolving pneumonia may cause collapse in the airways, and therefore crackles of a different character and timing can be heard.

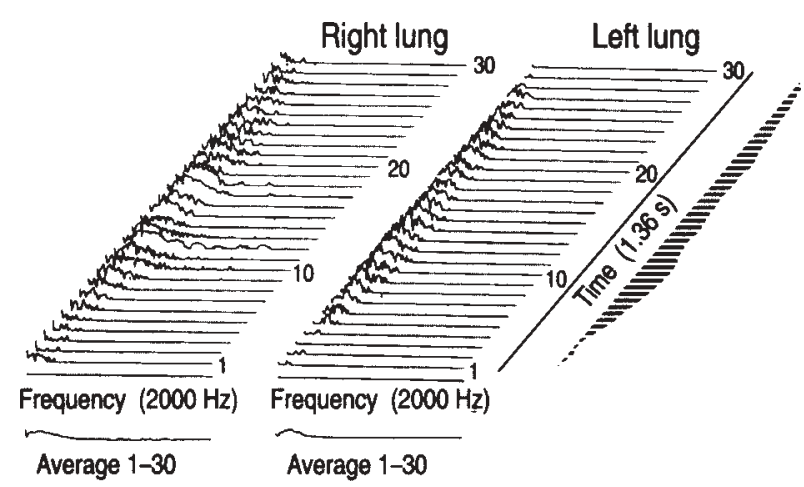

Fig. 6. - Serial spectra of the lung sounds of one patient with unilateral pneumonia. This patient has inspiratory crackling sounds in the pneumonic area of the right lung. The frequency spectrum of the right lung presents significantly higher sound components than the left one, which is healthy. (Reproduced by permission of Chest PIIRILÄ [14]).

According to LAËNNEC [2], the crackles in pneumonia resembled those in pulmonary oedema and haemoptysis. In Osler's Textbook of Medicine [80], the crackles in the early stages of pneumonia were described to be fine, whereas in resolving pneumonia crackles of all sizes occurred. Some authors consider the crackles of pneumonia to be fine at the acute stage of the disease and to become coarser when pneumonia is resolving [81]. FORGACS [5] characterized the pneumonic crackles as late inspiratory crackles, like the ones in fibrosing alveolitis.

In computerized objective sound analysis, the crackles in acute pneumonia have been shown to be midinspiratory and fairly coarse (2CD 9-11 ms), resembling crackles in patients with bronchiectasis. During recovery they are more end-inspiratory and shorter in duration, but also greater variation of crackle duration is then characteristic (2CD 6-11 ms) [61]. During recovery, the pneumonic crackles can resemble those in fibrosing alveolitis.

In unilateral pneumonia, simultaneous analysis of sounds from both lungs may be informative; an example of asymmetry in a serial FFT analysis due to unilateral pneumonia-induced crackles is presented in figure 6 . In the diseased lung, high frequency sound components due to crackling are clearly seen during inspiration.

\section{Crackles in sarcoidosis}

In sarcoidosis, granulomatous lesions are often present in the upper zones of the lungs, but usually no crackles are heard in auscultation of these areas. BAUGHMAN et al. [82] have studied the auscultatory findings in sarcoidosis complicated by fibrosis: the crackles were fine and late or mid-inspiratory. Compared to fibrosing alveolitis the crackles were far fewer, and according to HRCT scan results this was related to the different distribution of fibrosis in these two pulmonary diseases; basal subpleural fibrosis favoured crackling sounds.

\section{Expiratory crackles}

Coarse expiratory crackles have been reported to occur especially in chronic airway obstruction [5]. However, 
expiratory crackling sounds have also been found in many other pulmonary disorders $[13,14,61]$. Fine expiratory crackles have also been noted in fibrosing alveolitis $[13,61,71]$. The polarities of the initial deflections of expiratory crackles have been shown to be opposite to those in inspiration [11, 71, 83]. Expiratory crackles are usually much less frequent than inspiratory ones. Expiratory crackles, according to Forgacs' theory, possibly represent the closing sounds of small airways. Variations in respiratory pattern did not affect their timing or number in the study by WALSHAW et al. [71].

\section{Squawks}

Squawks are short musical sounds that have been described to occur in fibrotic pulmonary disorders. In the same patients, usually fine inspiratory crackling sounds can be heard $[2,5]$. Squawks are very short wheezes with a mean duration of 90-320 ms [84]. ForGaCs [5] explained that these sounds are generated when a closed airway suddenly opens in inspiration but for a brief moment the airway walls remain in light contact to each other; thus, the inflowing inspiratory air can cause the walls to oscillate, producing a wheezing sound. EARIS et $a l$. [84] have found that the squawks in extrinsic alveolitis were shorter in duration and later in timing than in other pulmonary diseases.

\section{Other crackle-like sounds}

Sound from pleural friction can sometimes resemble crackling sounds. Usually, however, the friction sound is very coarse and low in pitch. Ultrafine crackles have been described in subcutaneous emphysema [85]. This review is not dealing with these kinds of sounds.

\section{Summary and future perspectives}

The modern concept of the pathophysiology of crackles, opening or closing of single airways modified by the properties of surrounding tissue offer a fascinating basis to the study of acoustic properties of crackling sounds. Results of the modern computerized lung sound analysis can confirm this theory of the origin of crackles. The studies referred to in this review indicate that the timing and waveform characteristics of crackles have a certain discriminating power of pulmonary diseases and heart failure. Therefore, analysis of crackles could be helpful in differential diagnosis, and possibly also in early diagnosis of pulmonary diseases, both in pulmonary and in occupational medicine.

The number of crackles correlates to the severity of a pulmonary disease. Therefore, automatic crackle detection and counting methods have been developed for easy and objective assessment of sound samples of longer duration $[62,66]$. In future, automatic analysis of timing and waveform of crackles will also be possible. The development of computerized lung sound analysis enhances the possibility for clinical utilization of the information on crackles both in diagnosis and in follow-up of pulmonary diseases and possibly also in critical care units.

\footnotetext{
Acknowledgements: Support from the Finnish Lung Health Association (PP), the Ida Montin Foundation (PP) and the Paulo Foundation (AS) is acknowledged.
}

\section{References}

1. Epler GR, Carrington CB, Gaensler EA. Crackles (rales) in the interstitial pulmonary diseases. Chest 1978; 73: 333339.

2. Laënnec RLH. A treatise on the disease of the chest. Transl. J. Forbes. New York, Hafner Publishing Co., 1962; pp. 281384.

3. Cabot RC, Dodge HF. Frequency characteristics of heart and lung sounds. J Am Med Assoc 1925; 84: 1793-1795.

4. McKusick VA, Jenkins JT, Webb GN. The acoustic basis of chest examination. Am Rev Tuberc 1955; 72: 12-34.

5. Forgacs P. Lung sounds. London, Bailliere Tindall, 1978.

6. Nath AR, Capel LH. Inspiratory crackles - early and late. Thorax 1974; 29: 223-227.

7. Nath AR, Capel LH. Inspiratory crackles and mechanical events of breathing. Thorax 1974; 29: 695-698.

8. Forgacs P. The functional basis of pulmonary sounds. Chest 1978; 73: 399-405.

9. Kudoh S, Katsuyuki I, Kosaka K. Analysis of rales in patients with fibrosing alveolitis by a new phonopneumographic method using a sound spectrograph. Jap J Thorac Dis 1977; 8: 755-783.

10. Shirai F, Kudoh S, Shibuya A, Sada K, Mikami R. Crackles in asbestos workers: auscultation and lung sound analysis. Br J Dis Chest 1981; 75: 386-396.

11. Dalmasso F, Guarene MM, Spagnolo R, Benedetto G, Righini G. A computer system for timing and acoustical analysis of crackles: a study in cryptogenic fibrosing alveolitis. Bull Eur Physiopathol Respir 1984; 20: 139-144.

12. Holford SK. Discontinuous adventitious lung sounds: measurement, classification and modeling. Doctoral thesis. Cambridge; Massachusetts Institute of Technology, 1982.

13. Piirilä P, Sovijärvi ARA, Kaisla T, Rajala H-M, Katila T. Crackles in patients with fibrosing alveolitis, bronchiectasis, COPD and heart failure. Chest 1991; 99: 1076-1083.

14. Piirilä P. Change in crackle characteristics during the clinical course of pneumonia. Chest 1992; 102: 176-183.

15. Fredberg J, Holford SK. Discrete lung sounds: crackles (rales) as stress-relaxation quadrupoles. J Acoust Soc Am 1983; 73: 1036-1046.

16. Macklem PT, Fraser RG, Brown WG. Bronchial pressure measurements in emphysema and bronchitis. J Clin Invest 1965; 44: 897-905.

17. Murphy RLH, Sorensen K. Chest auscultation in the diagnosis of pulmonary asbestosis. J Occup Med 1973; 15: 272-276.

18. Workum P, Holford SK, DelBono E, Murphy RLH. The prevalence and character of crackles (rales) in young women without significant lung disease. Am Rev Respir Dis 1982; 126: 921-923. 
19. Thacker RE, Kraman SS. The prevalence of auscultatory crackles in subjects without lung disease. Chest 1982; 81: 672-674.

20. Dollfuss RE, Milic-Emili J, Bates DV. Regional ventilation of the lung studied with boluses of ${ }^{133}$ xenon. Respir Physiol 1967; 2: 234-246.

21. Connolly MJ, Crowley JJ, Vestal RE. Clinical significance of crepitations in elderly patients following acute hospital admission: a prospective study. Age Ageing 1992; Vol. 21(1): 43-48.

22. American Thoracic Society. Updated nomenclature for membership reaction. Reports of the ATS-ACCP ad hoc committee. Am Thorac Soc News 1977; 3: 5-6.

23. Moore BCJ. An introduction to the psychology of hearing. New York, Academic Press, 1982; pp. 1-73.

24. Ertel P, Lawrence M, Brown RK, Stern AM. Stethoscope acoustics. II. Transmission and filtration patterns. Circulation 1966; 24: 899-909.

25. Johnston FD, Kline EM. An acoustical study of the stethoscope. Arch Intern Med 1940; 65: 328-339.

26. Kindig JR, Beeson TP, Campbell RW, Andries F, Tavel ME. Acoustical performance of the stethoscope: a comparative analysis. Am J Heart 1982; 104: 269-275.

27. Charbonneau G, Sudraud M. Measure de la réponse en fréquence de quelques stéthoscopes usuels. Conséquence pour l'auscultation cardiaque et pulmonaire. Bull Eur Physiopathol Respir 1985; 21: 49-54.

28. Pekkarinen J, Stark J, Rautalahti M. Acoustic characteristics of stethoscopes. Proceedings of the 18th biennal Meeting of the Nordic Acoustical Society. Luleå 11-13, 5, 1990. The Acoustical Society of Sweden, 1990; pp. 383-388.

29. Knudsen VO. The sensitivity of the ear to small differences in intensity and frequency. Phys Rev 1923; 21: 84-102.

30. Rappaport MB, Sprague HB. Physiologic and physical laws that govern auscultation, and their clinical application. Am Heart J 1941; 21: 257-318.

31. Stewart GW. Problems suggested by an uncertainty principle in acoustics. J Acoust Soc Am 1931; 3: 325-329.

32. McKusick V. Cardiovascular sounds in health and disease. Baltimore, Williams \& Wilkins, 1958; pp. 59-70.

33. Fletcher H, Munson WA. Loudness, its definition, measurement and calculation. J Acoust Soc Am 1933; 5: 82-108.

34. Kingsbury BA. A direct comparison of the loudness of pure tones. Phys Rev 1927; 29: 588-600.

35. Mayer AM. Researchables in acoustics. Phil Mag J Sc 1876; 2: 500-506.

36. Schilling RSF, Hudges JPW, Dingwall-Fordyce I. Disagreement between observers in an epidemiological study of respiratory diseases. $\mathrm{Br}$ Med $J$ 1955; 1: 65-68.

37. Smyllie HC, Blendis LM, Armitage P. Observer disagreement in physical signs of the respiratory system. Lancet 1965; ii: 412-413.

38. Hudson LD, Conn RD, Matsubara RS, Pribble AH. Rales diagnostic uselessness of qualitative adjectives. Am Rev Respir Dis 1976; 3113 (No. 4, Part 2), p. 187 (Abstract).

39. Piirilä $P$, Kallio K, Katila T, et al. Crackle sound intensity in the auscultation of crackling sounds in fibrosing alveolitis and heart failure. The 17th International Conference on Lung Sounds, 24-26, 8, 1992, Helsinki, Finland, p. 26.

40. Cugell DW. Use of tape-recordings of respiratory sound and breathing pattern for instruction in pulmonary auscultation. Am Rev Respir Dis 1971; 104: 948-950.
41. Weiss EB, Carlson CJ. Recording of breath sounds. Am Rev Respir Dis 1972; 105: 835-839.

42. Druzgalski ChK, Donnerberg RL, Campbell RM. Techniques of recording respiratory sounds. J Clin Eng 1980; 5: 321-330.

43. Beck R, Gavriely N. The reproducibility of forced expiratory wheezes. Am Rev Respir Dis 1990; 141: 1418-1422.

44. Gavriely N, Palti Y, Alroy G, Grotberg JB. Measurement and theory of wheezing breath sounds. J Appl Physiol: Respirat Environ Exercise Physiol 1984; 57: 481-492.

45. Gavriely N, Palti Y, Alroy G. Spectral characteristics of normal breath sounds. J Appl Physiol 1981; 50(2): 307-314.

46. Pasterkamp H, Carson C, Daien D, Oh Y. Digital respirosonography: new images of lung sounds. Chest 1989; 96 : 1405-1412.

47. Ploysongsang Y, Martin RR, Ross WRD, Loudon RG, Macklem PT. Breath sounds and regional ventilation. Am Rev Respir Dis 1977; 116: 187-199.

48. Charbonneau G, Racineux JL, Sudraud M, Tuchais E. An accurate recording system and its use in breath sounds spectral analysis. J Appl Physiol: Respirat Environ Exercise Physiol 1983; 55: 1120-1127.

49. Murphy RLH, Holford SK, Knowler WC. Visual lungsound characterization by time-expanded wave-form analysis. $N$ Engl J Med 1977; 296: 968-971.

50. Schreiber JR, Anderson WF, Wegman MJ, Waring WW. Frequency analysis of breath sounds by phonopneumography. Med Instrum 1981; 15(5): 331-334.

51. Akasaka K, Konno K, Ono Y, et al. Acoustical studies on respiratory sounds in asthmatic patients. Tohoku J Exp Med 1975; 117: 323-333.

52. Mori M, Kinoshita K, Morinari H, Shiraishi T, Koike S, Murao S. Waveform and spectral analysis of crackles. Thorax 1980; 35: 843-850.

53. Workum P, DelBono EA, Holford SK, Murphy RLH. Observer agreement, chest auscultation and crackles in asbestos-exposed workers. Chest 1986; 89: 27-29.

54. Kraman SS. Does laryngeal noise contribute to the vesicular lung sound? Am Rev Respir Dis 1981; 124: 292-294.

55. Kraman SS. Does the vesicular lung sound come only from the lungs? Am Rev Respir Dis 1983; 128: 622-626.

56. Urquhart RB, McGhee J, Macleod JES, Banham SW, Moran F. The diagnostic value of pulmonary sounds: a preliminary study by computer-aided analysis. Comput Biol Med 1981; 139: 129-139.

57. Banham SW, Urquhart RB, Macleod JES, Moran F. Alteration in the low frequency lungs sounds in respiratory disorders associated with crackles. Eur J Respir Dis 1984; 65: 58-63.

58. Katila T, Piirilä P, Kallio K, Paajanen E, Rosqvist T, Sovijärvi ARA. Original waveform of lung sound crackles: a case study of the effect of high-pass filtration. J Appl Physiol 1991; 71(6): 2173-2177.

59. Cummiskey J, Williams TC, Krumpe PE, Guilleminault C. The detection and quantification of sleep apnea by tracheal sound recordings. Am Rev Respir Dis 1982; 126: 221-224.

60. O'Donnel D, Kraman S. Vesicular lung sound mapping by flow-gated phonopneumography. J Appl Physiol: Respirat Environ Exercise Physiol 1982; 53: 603-609.

61. Piirilä P. Acoustic properties of cough and crackling lung sounds in patients with pulmonary diseases. Doctoral thesis, Helsinki University, Helsinki 1992, ISBN 951-801-900-2. 
62. Kaisla T, Sovijärvi ARA, Piirilä P, Rajala H-M, Haltsonen S, Rosqvist T. Validated method for automatic detection of lung sound crackles. Med Biol Eng Comput 1991; 29: 517-521.

63. Rosqvist T, Kallio K, Paajanen E, et al. A toolkit for lung sound analysis. Med Biol Eng Comput 1995; (in press).

64. Henrici P. Fast Fourier methods in computational complex analysis. Siam Rev 1979; 21(4): 481-527.

65. Doi I, Ukita H, Homma Y, et al. A new method for the analysis of individual waveform and spectral characteristics of crackles: II. Standard values for fine and coarse crackles. In: The 14th International Conference on Lung Sounds. Winnipeg, Canada; International Lung Sounds Association, 1989; p. 11.

66. Sovijärvi ARA, Malmberg P, Kallio K, Paajanen E. Repeatability of breath sound parameters in healthy nonsmoking men and in patients with fibrosing alveolitis. Eur Respir $J$ 1994; 7 (Suppl. 18): p. 328 (Abstract).

67. Murphy RLH, DelBono E, Davidson F. Validation of an automatic crackle (rale) counter. Am Rev Respir Dis 1989; 140: 1017-1020.

68. Munakata M, Ukita H, Doi I, et al. Spectral and waveform characteristics of fine and coarse crackles. Thorax 1991; 46: 651-657.

69. Hoevers J, Loudon RG. Measuring crackles. Chest 1991; 98 : 1240-1243.

70. Sovijärvi ARA, Piirilä P, Luukkonen R. Enhanced diagnostic power with two-dimensional discriminant analysis of crackles in pulmonary disorders. Clin Physiol 1995; (submitted).

71. Walshaw MJ, Nisar M, Pearson MG, Calverley MB. Earis JE. Expiratory crackles in patients with fibrosing alveolitis. Chest 1990; 97: 407-409.

72. Mitchell CA, Charney M, Schoenberg JB. Early lung disease in asbestos-product workers. Lung 1978; 154: 261-272.

73. Smithers WG. Secular changes in asbestos in an asbestos factory: biological effects of asbestosis. Ann NY Acad Sci 1965; 132: 166.
74. Chowdhury SK, Majumder AK. Digital spectrum analysis of respiratory sound. IEEE Transact Biomed Eng 1981; 28: 784-788.

75. Dreesen WC, Dallavalle JM, Edwards TL, Miller JW, Sayers RR. A study of asbestosis in the asbestos textile industry. Public Health Bulletin 241, Washington, DC, Public Health Service, 1938.

76. Al Jarad N, Davies SW, Logan-Sinclair R, Rudd RM. Lung crackle characteristics in patients with asbestosis, asbestosrelated pleural disease and left ventricular failure using a timeexpanded waveform analysis: a comparative study. Respir Med 1994; 88: 37-46.

77. Al Jarad N, Strickland B, Bothamley G, Lock S, LoganSinclair R, Rudd RM. Diagnosis of asbestosis by a timeexpanded wave form analysis, auscultation and high resolution computed tomography: a comparative study. Thorax 1993; 48: 347-353.

78. Murphy RLH. Discontinuous adventitious lung sounds. Semin Respir Med 1985; 6: 210-219.

79. Mitchell CA. Lung sounds a suggested approach. Med J Austr 1983; 1: 308-309.

80. McGehee Harvey A, McKusick VA. Osler's textbook revisited. Appleton-Century-Crofts, 1967; pp. 176-177.

81. Pratt JH, Bushnell GE. In: Physical Diagnosis of Diseases of the Chest. Philadelphia, WB Saunders Co., 1925; pp. 50-57.

82. Baughman RP, Shipley RT, Loudon RG, Lower EE. Crackles in interstitial lung disease: comparisons of sarcoidosis and fibrosing alveolitis. Chest 1991; 100: 96-101.

83. Matsuzaki M. Polarity of crackle waveforms: a new index for crackle differentiation. Hokkaido J Med Sci 1985; 60: 104113.

84. Earis JE, Marsh K, Pearson MG, Ogilvie CM. The inspiratory squawk in extrinsic allergic alveolitis and other pulmonary fibroses. Thorax 1982; 37: 923-926.

85. Dalmasso F, Righini G, Prota R, Righini P. The "ultrafine" crackles. International Lung Sounds Association, The 17th International Conference on Lung Sounds. Helsinki, Finland, 1992; 9: p. 54. 